\title{
Construction of Fully Conjugated Covalent Organic Frameworks via Facile Linkage Conversion for Efficient Photoenzymatic Catalysis
}

\author{
Yuancheng Wang, ${ }^{\dagger,+}$ Hui Liu,${ }^{\dagger,+}$ Qingyan Pan, ${ }^{\dagger}$ Chenyu Wu, ${ }^{\dagger}$ Wenbo Hao, ${ }^{\dagger} \mathrm{Jie} \mathrm{Xu},{ }^{\dagger}$ \\ Renzeng Chen,${ }^{\dagger}$ Jian Liu, ${ }^{\ddagger}$ Zhibo Li, ${ }^{*}, \dagger$ and Yingjie Zhao ${ }^{*}, \dagger$
}

${ }^{\dagger}$ Key Laboratory of Biobased Polymer Materials, Shandong Provincial Education Department; College of Polymer Science and Engineering, Qingdao University of Science and Technology, Qingdao 266042, China

* College of Materials Science and Engineering, Qingdao University of Science and Technology, Qingdao 266042, China

[*] Corresponding Authors: zbli@qust.edu.cn, yz@qust.edu.cn

$\left.{ }^{+}\right]$These authors contributed equally to this work.

\section{Supporting Information}

Table of Contents

\section{Supporting Methods}

1.1 General materials and methods

1.2 Synthesis procedure

\section{Supporting Figures and Legends}

Figure S1: FT-IR spectra

Figure S2: Thermogravimetric analysis profiles

Figure S3: PXRD analysis and structure simulation

Table S1-S4: Fractional atomic coordinates of the COFs

Figure S4: Pore size and pore size distribution profiles 
Figure S6: The process of photocatalytic NADH regeneration

Figure S7: Solid-state absorption spectrum

Figure S8-S11: NADH regeneration results

Figure S12: Photocurrent profiles

Figure S13: Electrochemical CV curves

Figure S14-S23: NMR spectra 


\section{Supporting Methods}

\subsection{General materials and methods}

Unless otherwise specified, all reactions were performed in dried glassware under ambient atmosphere. All other reagents were purchased commercially and used without further purification. Organic solvents including ethanol, dichloromethane (DCM), petroleum ether, 2,2'-bipyridine, tris(2-hydroxy ethyl)amine (TEOA), triethanolamine dichloro(pentamethylcyclopenta-dienyl) rhodium(III) dimer, phosphate buffer, nicotinamide adenine dinucleotide $\left(\mathrm{NAD}^{+}\right), \alpha$ ketoglutarate, diammonium hydrogen phosphate, trifluoromethane sulfonic acid, trifluoroacetic acid and benzaldehyde were purchased from Adamas; 1,2Dichlorobenzene, n-butanol and 1,4-dioxane were purchased from Alfa Aesar; dilute hydrochloric acid was purchased from Yantai Far East Fine Chemical Co., Ltd. All aqueous solutions were prepared with Milli-Q water.

${ }^{1} \mathrm{H}$ and ${ }^{13} \mathrm{C}$ NMR spectra were performed on $400 \mathrm{MHz}$ spectrometers (Bruker AVANCE NEO 400 Ascend) in the indicated solvents at room temperature. High resolution solid-state NMR spectra were recorded on Agilent NMR Spectrometer (60054-ASC) using a standard CP pulse sequence probe with $4 \mathrm{~mm}$ (outside diameter) zirconia rotors. Mass spectra were recorded with Waters GCT high-resolution mass spectrometer.

Transmission electron microscope (TEM) were performed on a JEM-2100 electron microscope with an accelerating voltage of $200 \mathrm{kV}$.

TGA was carried out on an American TA-Q20 in nitrogen atmosphere using a $10{ }^{\circ} \mathrm{C} / \mathrm{min}$ ramp without equilibration delay.

The liquid UV-Vis absorbance was measured by UV spectrophotometer (HITACHI, U-2910). The Solid-state UV-Vis absorbance were measured by UV spectrophotometer (HITACHI, U-3900).

Powder X-ray diffraction (PXRD) patterns were obtained on a PANalytical 
Empyrean X-Ray diffractometer with $\mathrm{Cu} \mathrm{K \alpha}$ line focused radiation at $40 \mathrm{kV}$ and $40 \mathrm{~mA}$ from $2 \theta=1.5^{\circ}$ up to $40^{\circ}$ with $0.02^{\circ}$ increment by Bragg-Brentano. The powdered sample was added to the glass and compacted for measurement.

$\mathrm{N}_{2}$ adsorption isotherms were measured up to 1 bar at $77 \mathrm{~K}$ using a Micrometrics ASAP 2460 surface area analyzer. Prior to measurements, samples (ca. $50 \mathrm{mg}$ ) were degassed for over $12 \mathrm{~h}$ at $120{ }^{\circ} \mathrm{C}$. UHP grade $\mathrm{N}_{2}$ and He were used throughout the adsorption experiments. Oil-free vacuum pumps and oil-free pressure regulators were used for measurements to prevent contamination of the samples during the degassing process and isotherm measurement.

Cyclic voltammetry (CV) was performed using a standard one compartment, three electrode electrochemical cell attached to an CHI 760E Electrochemical Workstation. The $\mathrm{Ag} / \mathrm{AgCl}$ aqueous electrode was used as reference electrode. Glass-carbon was used as the working electrode, and $\mathrm{Pt}$ was used as the counter electrode. Tetrabutylammonium hexafluorophosphate $(0.1 \mathrm{M})$ in acetonitrile was used as electrolyte.

Photocatalytic NADH Production: Photo regeneration of NADH was irradiated with a xenon lamp $(300 \mathrm{~W})$ through a $420 \mathrm{~nm}$ cut off filter, avoiding the UV light-induced damage of the enzyme with a distance of $10 \mathrm{~cm}$. The photocatalytic regeneration of NADH was carried out as follows. The reaction was performed in a quartz reactor. The reaction medium was composed of $\left[\mathrm{Cp}^{*} \mathrm{Rh}(\mathrm{bpy})(\mathrm{H})\right]^{+}(0.75 \mu \mathrm{mol}), \beta-\mathrm{NAD}^{+}(3 \mu \mathrm{mol})$, TEOA (2.01 mmol), $600 \mu \mathrm{L}$ of $4 \mathrm{M} \mathrm{HCl}$ solution and COF $(3 \mathrm{mg})$ in $2.1 \mathrm{~mL}$ of phosphate buffer $(100 \mathrm{mM}, \mathrm{pH}=7.0)$. The reactor was initially allowed to equilibriate in dark for 30 minutes, following which it was exposed to visible light. The regeneration of NADH was monitored by UV-vis spectrophotometer (U-3900, HITACHI). NADH has peak absorption at $340 \mathrm{~nm}$ with an extinction coefficient of $6220 \mathrm{M}^{-1} \mathrm{~cm}^{-1}$. During the illumination, the concentration of $\mathrm{NADH}$ was estimated by measuring the absorbance of the diluted reaction system at $340 \mathrm{~nm}$. 


\subsection{Synthesis procedure}

1,3,5-tris(4-formylphenyl)-benzene and 2,4,6-tris(4-formylphenyl)-1,3,5-triazine were prepared according to the references. ${ }^{\mathrm{S} 1-\mathrm{S} 2}$

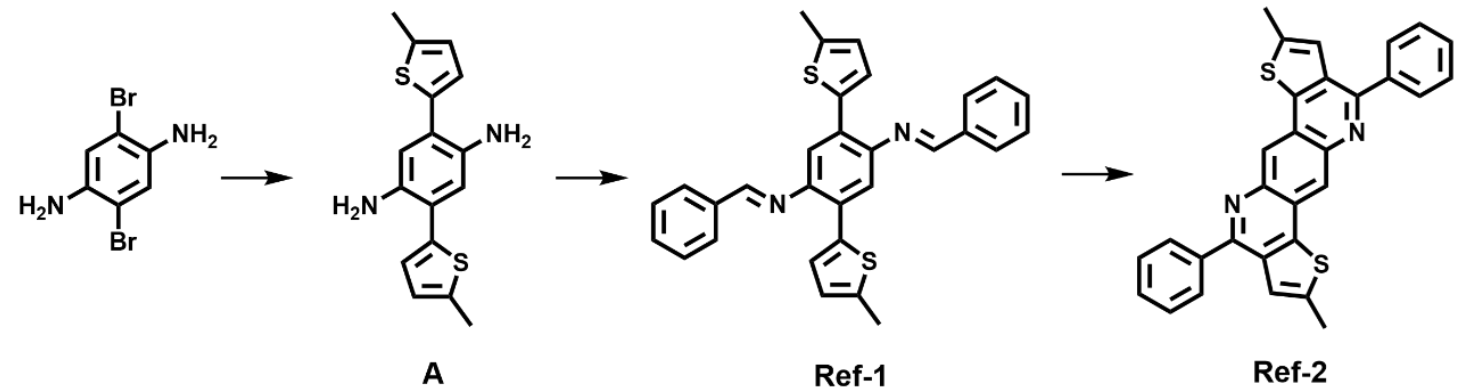

Synthesis of 2,5-bis(5-methylthiophen-2-yl)benzene-1,4-diamine (A).

A mixture of 2,5-dibromobenzene-1,4-diamine (1.00 g, $3.76 \mathrm{mmol}), 4,4,5,5$-Tetra methyl-2-(5-methyl-2-thienyl)-1,3,2-dioxaborolane (2.53 g, $11.28 \mathrm{mmol}), \mathrm{Pd}_{2}(\mathrm{dba})_{3}$ (172.2 $\mathrm{mg}, 0.19 \mathrm{mmol}$ ) and Xphos $(181.2 \mathrm{mg}, 0.38 \mathrm{mmol})$ in the mixed solvent containing tetrahydrofuran $(50 \mathrm{~mL})$ and $2.0 \mathrm{M} \mathrm{K}_{2} \mathrm{CO}_{3}(\mathrm{aq})(15 \mathrm{~mL})$ was refluxed at $80{ }^{\circ} \mathrm{C}$ under nitrogen overnight. After cooling down to room temperature, the mixture was extracted with ethyl acetate. The organic phase was dried with $\mathrm{MgSO}_{4}$ and condensed under reduced pressure. The residue was purified by chromatography $\left(\mathrm{SiO}_{2}\right.$, $50 \%$ petroleum ether in dichloromethane) to give the product as light yellow solid powder (0.93 g, 82.1\%). ${ }^{1} \mathrm{H}$ NMR (400 MHz, DMSO-d 6 , $\left.\delta\right): ~ 7.04(\mathrm{~d}, J=3.5 \mathrm{~Hz}, 2 \mathrm{H})$, $6.80\left(\mathrm{dd}, J_{1}=1.2 \mathrm{~Hz}, J_{2}=3.5 \mathrm{~Hz}, 2 \mathrm{H}\right), 6.73(\mathrm{~s}, 2 \mathrm{H}), 4.41(\mathrm{~s}, 4 \mathrm{H}), 2.46(\mathrm{~d}, J=1.1 \mathrm{~Hz}$, $6 \mathrm{H}) .{ }^{13} \mathrm{C}$ NMR (100 MHz, DMSO-d $\left.6, \delta\right): 139.4,138.6,136.7,126.5,125.6,120.5,117.8$, 15.4. HRMS (EI) m/z: [M+] calcd. for $\mathrm{C}_{16} \mathrm{H}_{16} \mathrm{~N}_{2} \mathrm{~S}_{2} 300.0755$; found 300.0753 .

\section{Synthesis of model compound Ref-1}

To a $25 \mathrm{~mL}$ flask was added compound A (100 mg, $0.33 \mathrm{mmol})$, benzaldehyde (106.0 $\mathrm{mg}, 1.00 \mathrm{mmol}$ ), $5 \mathrm{~mL}$ ethanol and $1 \mathrm{~mL}$ chloroform. The mixture was refluxed overnight and then dropped into $20 \mathrm{~mL}$ cold ethanol. The precipitate was centrifuged and washed with ethanol and acetone before dried to obtain yellow solid (99\% yield). ${ }^{1} \mathrm{H}$ NMR (400 MHz, $\left.\mathrm{CDCl}_{2} \mathrm{CDCl}_{2}, \delta\right): 8.62(\mathrm{~s}, 2 \mathrm{H}), 8.10\left(\mathrm{dd}, J_{1}=3.2 \mathrm{~Hz}, J_{2}=6.3 \mathrm{~Hz}\right.$ 
4H), $7.63(\mathrm{t}, J=3.2 \mathrm{~Hz}, 6 \mathrm{H}), 7.42(\mathrm{~s}, 2 \mathrm{H}), 7.39$ (d, $J=3.6 \mathrm{~Hz}, 2 \mathrm{H}), 6.84$ (dd, $J_{1}=3.6$ $\left.\mathrm{Hz}, J_{2}=1.3 \mathrm{~Hz}, 2 \mathrm{H}\right), 2.58(\mathrm{~d}, J=1.0 \mathrm{~Hz}, 6 \mathrm{H}) .{ }^{13} \mathrm{C} \mathrm{NMR}\left(100 \mathrm{MHz}, \mathrm{CDCl}_{2} \mathrm{CDCl}_{2}, \delta\right)$ : $160.0,146.2,142.5,137.7,136.3,131.8,129.6,129.2,127.8,126.3,125.6,117.3,15.6$. HRMS (EI) m/z: [M+] calcd. for $\mathrm{C}_{30} \mathrm{H}_{24} \mathrm{~N}_{2} \mathrm{~S}_{2}$ 476.1381; found 476.1383 .

\section{Synthesis of model compound Ref-2}

To a screw cap teflon-sealed tube was added Ref-1 (100 mg, $0.21 \mathrm{mmol})$ and $4 \mathrm{~mL}$ dried toluene. After bubbling with oxygen for $10 \mathrm{~min}, 2 \mathrm{ml}$ trifluoro acetic acid was added to the tube and then the tube was sealed. The reaction mixture was stirred at $100{ }^{\circ} \mathrm{C}$ for $24 \mathrm{~h}$ under oxygen atmosphere. After cooling to room temperature, the solvent was removed under vacuum and the crude product was recrystallized with dimethyl sulfoxide, filtered and washed with ethanol to obtain yellow crystal $(88.2 \mathrm{mg}, 89 \%) .{ }^{1} \mathrm{H}$ NMR (400 MHz, $\left.\mathrm{CDCl}_{2} \mathrm{CDCl}_{2}, \delta\right): 8.87$ (s, 2H), 7.89 (d, J=7.0 Hz, 4H), 7.51-7.56 (m,

6H), 7.28 (s, 2H), 2.63 (s, 6H). ${ }^{13} \mathrm{C}$ NMR (100 MHz, $\left.\mathrm{CDCl}_{2} \mathrm{CDCl}_{2}, \delta\right): 155.6,145.2$, 141.9, 141.6, 140.1, 132.4, 129.6, 129.5, 128.8, 124.1, 123.4, 123.4, 16.4. HRMS (EI) $\mathrm{m} / \mathrm{z}:\left[\mathrm{M}^{+}\right]$calcd. for $\mathrm{C}_{30} \mathrm{H}_{20} \mathrm{~N}_{2} \mathrm{~S}_{2}$ 472.1068; found 472.1061.

\section{Synthesis of B-COF-1.}

By condensing compound A (35.0 mg, $0.116 \mathrm{mmol}$ ) and 1,3,5-tris(4-formylphenyl)benzene (30.3 mg, $0.078 \mathrm{mmol}$ ) in the mixture of 1,2-dichlorobenzene/n-butanol/acetic acid (8:2:1, by volume) at $120^{\circ} \mathrm{C}$ for $72 \mathrm{~h}, \mathrm{~B}-\mathrm{COF}-1$ was isolated as yellowish orange powder insoluble in common organic solvents $\left({ }^{13} \mathrm{C} \mathrm{CP} / \mathrm{MAS}\right.$ spectra shown as Figure $1)$.

\section{Synthesis of T-COF-1.}

By condensing compound A (35.0 mg, $0.116 \mathrm{mmol}$ ) and 2,4,6-tris(4-formylphenyl)1,3,5-triazine (30.6 $\mathrm{mg}, 0.078 \mathrm{mmol}$ ) in the mixture of 1,2-dichlorobenzene/nbutanol/acetic acid (8:2:1, by volume) at $120{ }^{\circ} \mathrm{C}$ for $72 \mathrm{~h}$, B-COF-1 was isolated as orange red powder insoluble in common organic solvents $\left({ }^{13} \mathrm{C} \mathrm{CP} / \mathrm{MAS}\right.$ spectra shown as Figure 1). 


\section{Synthesis of B-COF-2.}

B-COF-1 (50 mg) and $3 \mathrm{~mL}$ dried toluene was added to a screw cap teflon-sealed tube. After bubbling with oxygen for $10 \mathrm{~min}, 2 \mathrm{ml}$ trifluoro acetic acid was added to the tube and then the tube was sealed and heated at $100{ }^{\circ} \mathrm{C}$ for 2 days. B-COF-2 was isolated as yellow powder insoluble in common organic solvents $\left({ }^{13} \mathrm{C} \mathrm{CP} / \mathrm{MAS}\right.$ spectra shown as Figure 1).

\section{Synthesis of T-COF-2.}

T-COF-1 (50 mg) and $3 \mathrm{~mL}$ dried toluene was added to a screw cap teflon-sealed tube. After bubbling with oxygen for $10 \mathrm{~min}, 2 \mathrm{ml}$ trifluoro acetic acid was added to the tube and then the tube was sealed and heated at $100{ }^{\circ} \mathrm{C}$ for 2 days. T-COF-2 was isolated as yellow powder insoluble in common organic solvents $\left({ }^{13} \mathrm{C} \mathrm{CP} / \mathrm{MAS}\right.$ spectra shown as Figure 1). 


\section{Supporting Figures and Legends}
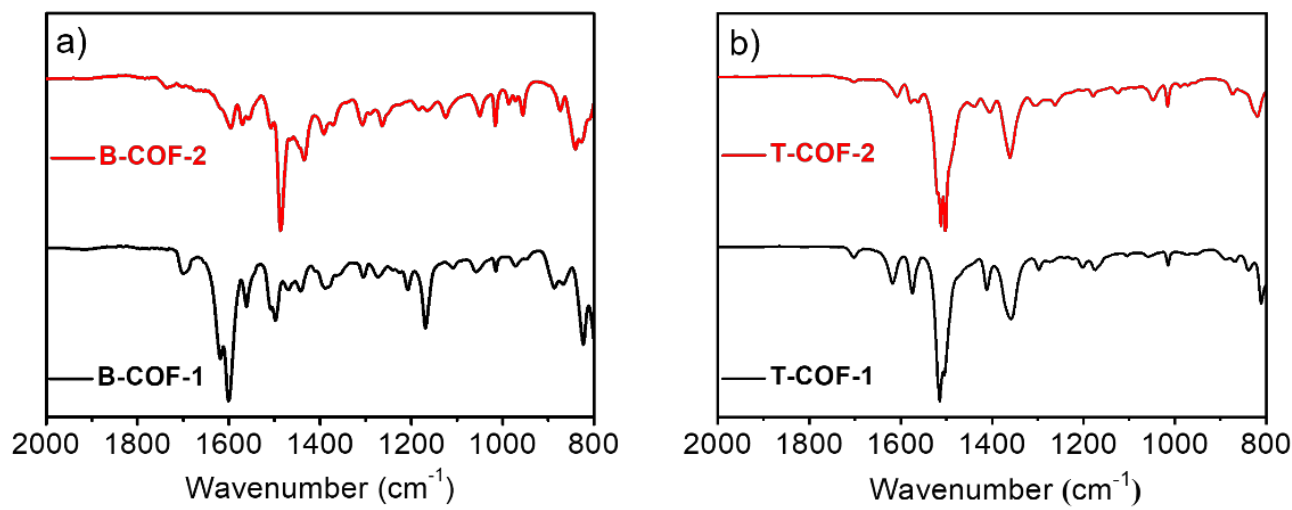

Figure S1. The FT-IR spectra of B-COF-1, 2 (a) and T-COF-1, 2 (b).

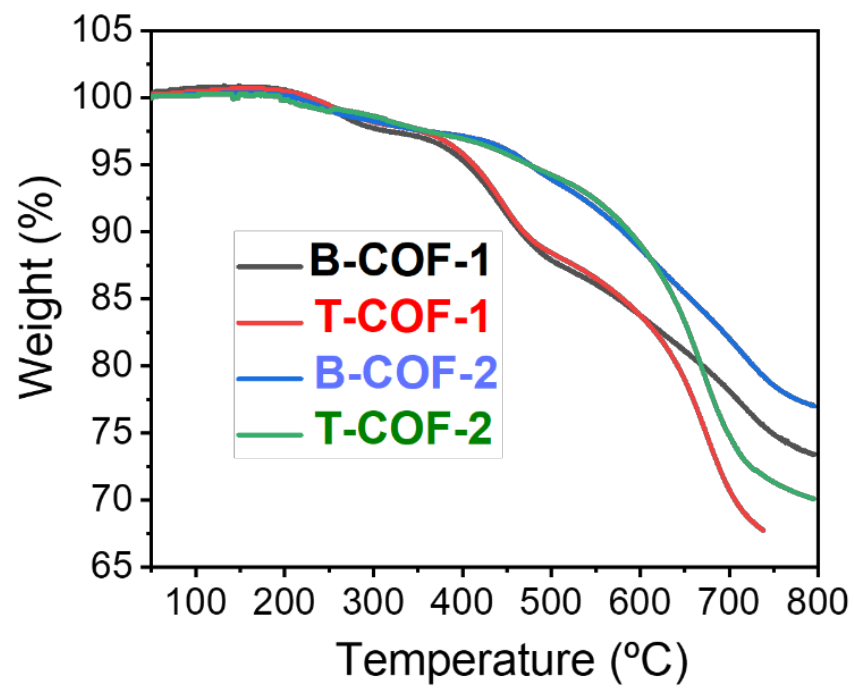

Figure S2. The thermogravimetric analysis profiles of B-COF-1, 2 and T-COF-1, 2. 

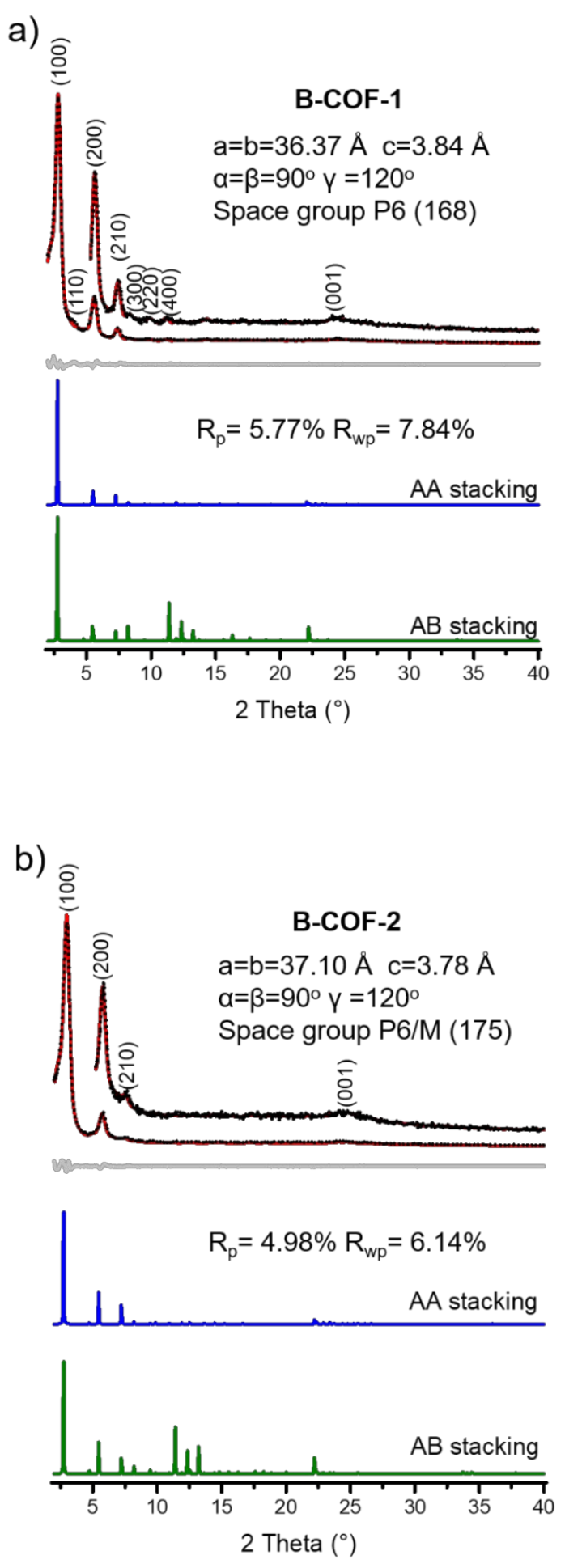
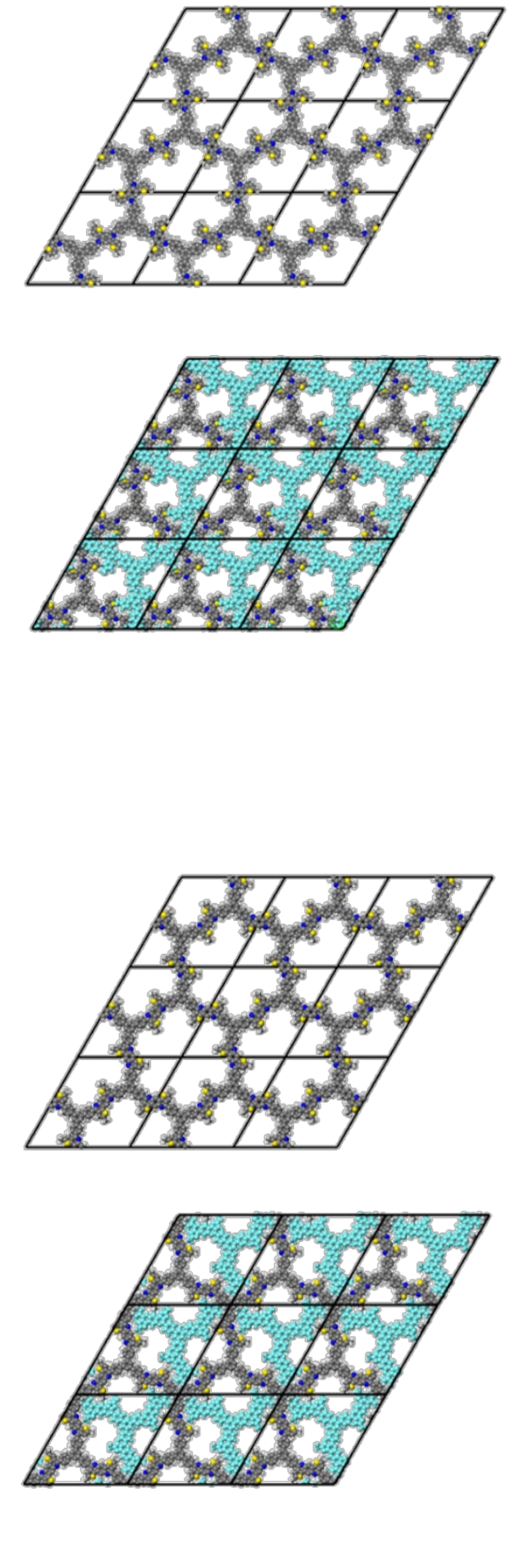
c)
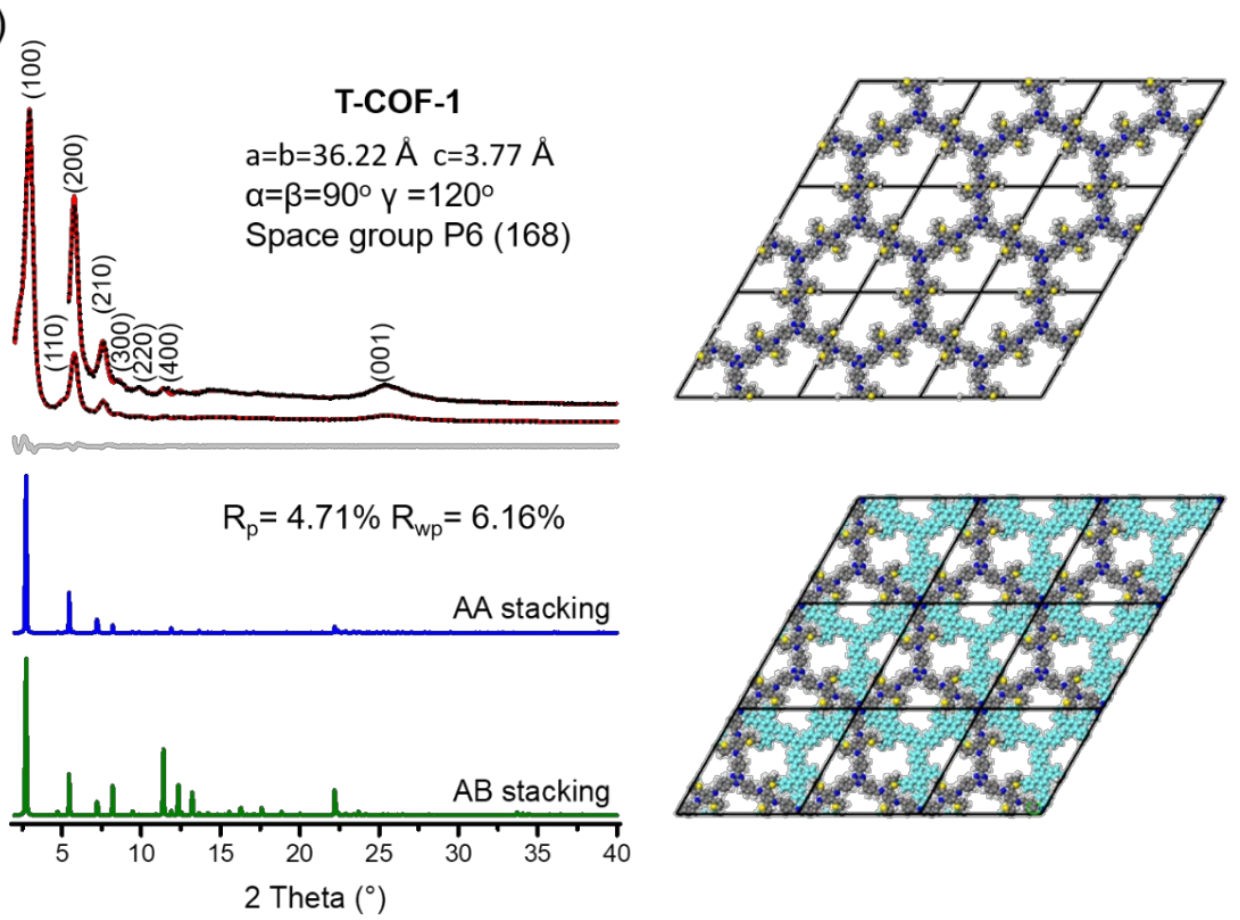

d)
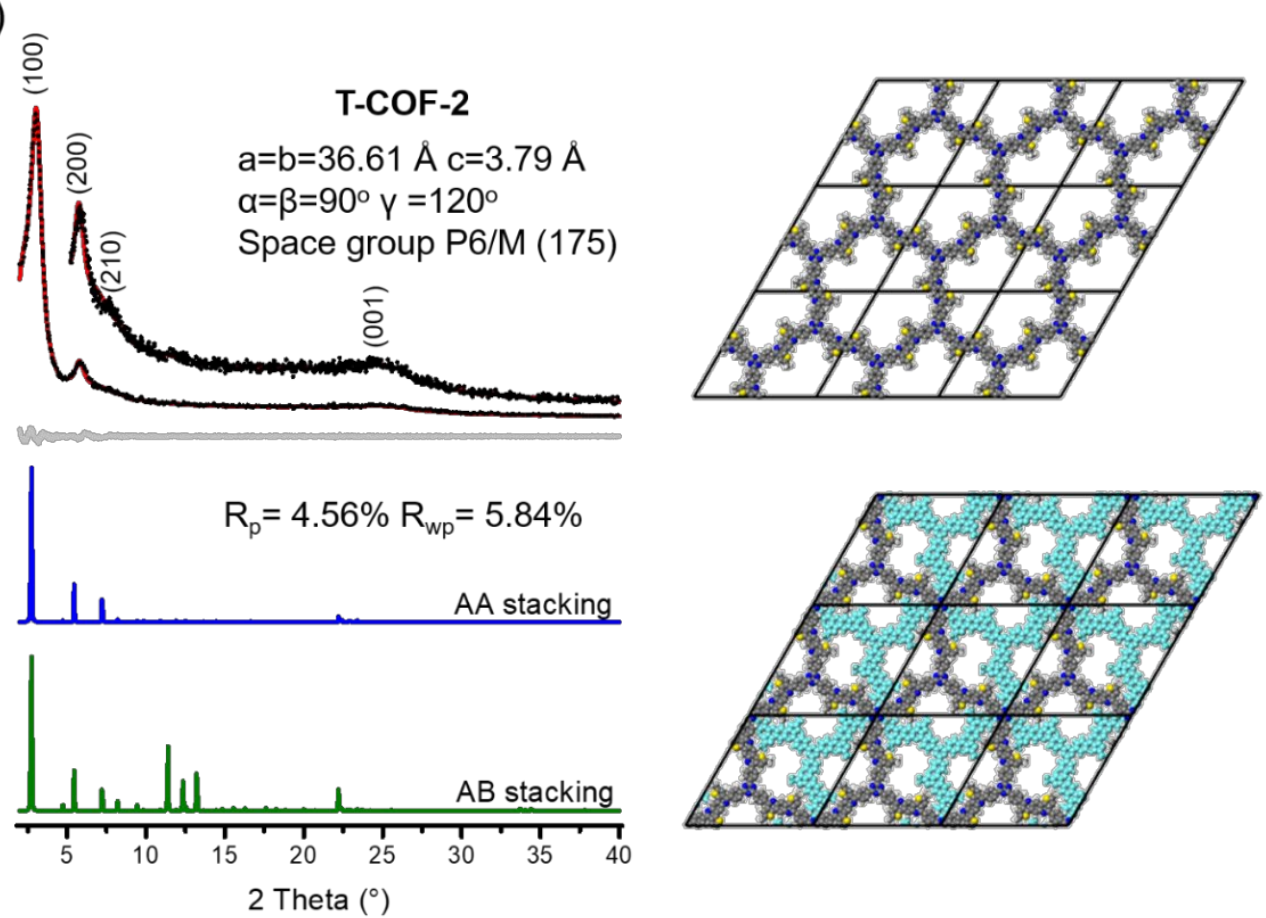

Figure S3. a) Indexed experimental (black), Pawley-refined (red) PXRD patterns with their difference(gray) and the theoretical patterns of AA stacking model (blue) and ABstacking model (green) of B-COF-1. Inset: zoomed view of the detailed PXRD profile without primary peaks; for B-COF-2, T-COF-1 and T-COF-2, see (b), (c) and (d). 
Table S1. Fractional atomic coordinates for the unit cell of B-COF-1 with AA stacking.

\begin{tabular}{|l|r|r|r|r|r|r|r|}
\hline \multicolumn{7}{|c|}{$\mathrm{P} 6(168)$} \\
\hline \multicolumn{7}{|c|}{$\mathrm{a}=\mathrm{b}=36.3649 \AA \mathrm{c}=3.8378 \AA, \alpha=\beta=90^{\circ}, \gamma=120^{\circ}$} \\
\hline $\mathrm{C} 1$ & 1.4071 & 1.56021 & 0.83586 & $\mathrm{C} 17$ & 1.9305 & 1.59623 & 1.1563 \\
\hline C2 & 1.4284 & 1.60225 & 0.95656 & $\mathrm{C} 18$ & 1.90079 & 1.56109 & 1.33558 \\
\hline C3 & 1.41095 & 1.62841 & 0.90796 & $\mathrm{C} 19$ & 1.07648 & 1.36818 & 1.05197 \\
\hline C4 & 1.37221 & 1.6136 & 0.72924 & $\mathrm{H} 20$ & 1.45773 & 1.61456 & 1.10133 \\
\hline C5 & 1.35193 & 1.57187 & 0.59614 & $\mathrm{H} 21$ & 1.42718 & 1.65961 & 1.02544 \\
\hline C6 & 1.36892 & 1.54536 & 0.65314 & $\mathrm{H} 22$ & 1.32296 & 1.55952 & 0.44605 \\
\hline C7 & 1.35231 & 1.64086 & 0.69696 & $\mathrm{H} 23$ & 1.35219 & 1.51318 & 0.55383 \\
\hline C8 & 1.3775 & 1.68539 & 0.69354 & $\mathrm{H} 24$ & 1.41162 & 1.69983 & 0.69784 \\
\hline C9 & 1.46896 & 1.89211 & 0.91417 & $\mathrm{H} 25$ & 1.50196 & 1.90598 & 0.84055 \\
\hline N10 & 1.45427 & 1.9156 & 1.07203 & $\mathrm{H} 26$ & 1.42221 & 1.46095 & 1.17004 \\
\hline C11 & 1.47722 & 1.95624 & 1.19027 & $\mathrm{H} 27$ & 1.89699 & 1.50439 & 1.55009 \\
\hline C12 & 1.45614 & 1.47802 & 1.20808 & $\mathrm{H} 28$ & 1.87022 & 1.55617 & 1.41905 \\
\hline C13 & 1.4777 & 1.45585 & 1.31584 & $\mathrm{H} 29$ & 1.08074 & 1.35296 & 1.28685 \\
\hline C14 & 1.95498 & 1.54705 & 1.26545 & $\mathrm{H} 30$ & 1.10539 & 1.38061 & 0.88771 \\
\hline C15 & 1.91502 & 1.53338 & 1.40294 & $\mathrm{H} 31$ & 1.04884 & 1.34393 & 0.90221 \\
\hline S16 & 1.97626 & 1.59575 & 1.06393 & & & & \\
\hline
\end{tabular}


Table S2. Fractional atomic coordinates for the unit cell of B-COF-2 with AA stacking.

\begin{tabular}{|c|c|c|c|c|c|c|c|}
\hline \multicolumn{7}{|c|}{$\mathrm{a}=\mathrm{b}=37.0995 \AA \mathrm{A}, \mathrm{c}=3.78 \AA \alpha=\beta=90^{\circ} \gamma=120^{\circ}$} \\
\hline $\mathrm{H} 1$ & -0.08646 & -0.71993 & -0.22766 & $\mathrm{C} 15$ & -0.58727 & -0.54699 & 0 \\
\hline $\mathrm{C} 2$ & -0.24303 & -0.63709 & 0 & $\mathrm{C} 16$ & -0.91617 & -0.3893 & 0 \\
\hline C3 & -0.2274 & -0.6649 & 0 & $\mathrm{C} 17$ & -0.09618 & -0.65271 & 0 \\
\hline C4 & -0.18471 & -0.65093 & 0 & $\mathrm{C} 18$ & -0.0629 & -0.65947 & 0 \\
\hline C5 & -0.1547 & -0.60833 & 0 & $\mathrm{~S} 19$ & -0.01536 & -0.61567 & 0 \\
\hline C6 & -0.17034 & -0.58054 & 0 & $\mathrm{C} 20$ & -0.068 & -0.70204 & 0 \\
\hline C7 & -0.21289 & -0.59431 & 0 & $\mathrm{H} 21$ & -0.24718 & -0.69815 & 0 \\
\hline C8 & -0.10769 & -0.58986 & 0 & $\mathrm{H} 22$ & -0.17738 & -0.675 & 0 \\
\hline N9 & -0.08536 & -0.54735 & 0 & $\mathrm{H} 23$ & -0.14969 & -0.54718 & 0 \\
\hline C10 & -0.04326 & -0.5241 & 0 & $\mathrm{H} 24$ & -0.22069 & -0.57004 & 0 \\
\hline C11 & -0.01924 & -0.54366 & 0 & $\mathrm{H} 25$ & -0.95651 & -0.53346 & 0 \\
\hline C12 & -0.97593 & -0.51932 & 0 & $\mathrm{H} 26$ & -0.71696 & -0.40809 & 0 \\
\hline C13 & -0.71036 & -0.34764 & 0 & $\mathrm{H} 27$ & -0.1267 & -0.679 & 0 \\
\hline C14 & -0.69521 & -0.37576 & 0 & $\mathrm{H} 28$ & -0.0374 & -0.70063 & 0 \\
\hline
\end{tabular}


Table S3. Fractional atomic coordinates for the unit cell of T-COF-1 with AA stacking.

\begin{tabular}{|c|c|c|c|c|c|c|c|}
\hline \multicolumn{8}{|c|}{ P6 (168) } \\
\hline \multicolumn{8}{|c|}{$\mathrm{a}=\mathrm{b}=36.2164 \AA, \mathrm{c}=3.7705 \AA \alpha=\beta=90^{\circ} \gamma=120^{\circ}$} \\
\hline $\mathrm{C} 1$ & -0.5959 & -0.4408 & 0.83953 & $\mathrm{C} 16$ & -0.5967 & -0.6664 & 1.11831 \\
\hline $\mathrm{C} 2$ & -0.5707 & -0.3967 & 0.89521 & $\mathrm{C} 17$ & -0.561 & -0.6613 & 1.29197 \\
\hline $\mathrm{C} 3$ & -0.5876 & -0.37 & 0.84053 & $\mathrm{C} 18$ & -0.533 & -0.6192 & 1.36305 \\
\hline $\mathrm{C} 4$ & -0.6302 & -0.3868 & 0.73333 & $\mathrm{C} 19$ & -0.3674 & -0.291 & 1.01108 \\
\hline $\mathrm{C} 5$ & -0.6551 & -0.4309 & 0.67037 & $\mathrm{H} 20$ & -0.5382 & -0.3828 & 0.98739 \\
\hline C6 & -0.638 & -0.4576 & 0.72165 & $\mathrm{H} 21$ & -0.5676 & -0.3362 & 0.89328 \\
\hline $\mathrm{C} 7$ & -0.6491 & -0.359 & 0.70627 & $\mathrm{H} 22$ & -0.6879 & -0.4448 & 0.58488 \\
\hline N8 & -0.6238 & -0.3159 & 0.70714 & $\mathrm{H} 23$ & -0.658 & -0.4915 & 0.67568 \\
\hline $\mathrm{C} 9$ & -0.5301 & -0.1095 & 0.91628 & $\mathrm{H} 24$ & -0.4965 & -0.0964 & 0.86175 \\
\hline N10 & -0.5452 & -0.0853 & 1.05641 & $\mathrm{H} 25$ & -0.5782 & -0.5397 & 1.15988 \\
\hline C11 & -0.5226 & -0.0441 & 1.16964 & H 26 & -0.5558 & -0.6871 & 1.36935 \\
\hline $\mathrm{C} 12$ & -0.5441 & -0.5224 & 1.18968 & $\mathrm{H} 27$ & -0.5036 & -0.6085 & 1.50791 \\
\hline C13 & -0.5222 & -0.5446 & 1.29253 & $\mathrm{H} 28$ & -0.3797 & -0.2744 & 0.84219 \\
\hline C14 & -0.4531 & -0.4074 & 1.23311 & $\mathrm{H} 29$ & -0.3431 & -0.2947 & 0.86097 \\
\hline S15 & -0.5963 & -0.6199 & 1.03543 & $\mathrm{H} 30$ & -0.3521 & -0.2712 & 1.2487 \\
\hline
\end{tabular}


Table S4. Fractional atomic coordinates for the unit cell of T-COF-2 with AA stacking.

\begin{tabular}{|c|c|c|c|c|c|c|c|}
\hline \multicolumn{7}{|c|}{$\mathrm{P} 6 / \mathrm{M}(175)$} \\
\hline $\mathrm{H} 1$ & 0.91174 & 0.27701 & -0.22744 & $\mathrm{C} 15$ & 0.41148 & 0.45262 & 0 \\
\hline C2 & 0.75463 & 0.36192 & 0 & $\mathrm{C} 16$ & 0.08527 & 0.61215 & 0 \\
\hline C3 & 0.76928 & 0.33318 & 0 & $\mathrm{C} 17$ & 0.9021 & 0.34525 & 0 \\
\hline C4 & 0.81247 & 0.34709 & 0 & $\mathrm{C} 18$ & 0.93575 & 0.33827 & 0 \\
\hline C5 & 0.84303 & 0.39045 & 0 & $\mathrm{~S} 19$ & 0.98399 & 0.38257 & 0 \\
\hline C6 & 0.82736 & 0.41894 & 0 & $\mathrm{C} 20$ & 0.93045 & 0.29508 & 0 \\
\hline C7 & 0.78425 & 0.40503 & 0 & $\mathrm{H} 21$ & 0.74725 & 0.29955 & 0 \\
\hline C8 & 0.89065 & 0.40906 & 0 & $\mathrm{H} 22$ & 0.81966 & 0.32253 & 0 \\
\hline N9 & 0.91337 & 0.45214 & 0 & $\mathrm{H} 23$ & 0.84831 & 0.45274 & 0 \\
\hline C10 & 0.95605 & 0.4756 & 0 & $\mathrm{H} 24$ & 0.77424 & 0.4283 & 0 \\
\hline C11 & 0.98029 & 0.45568 & 0 & $\mathrm{H} 25$ & 0.04401 & 0.46598 & 0 \\
\hline C12 & 0.02441 & 0.48039 & 0 & $\mathrm{H} 26$ & 0.87114 & 0.31867 & 0 \\
\hline C13 & 0.29118 & 0.65297 & 0 & $\mathrm{H} 27$ & 0.96142 & 0.29643 & 0 \\
\hline N14 & 0.3051 & 0.62484 & 0 & & & & 0 \\
\hline
\end{tabular}



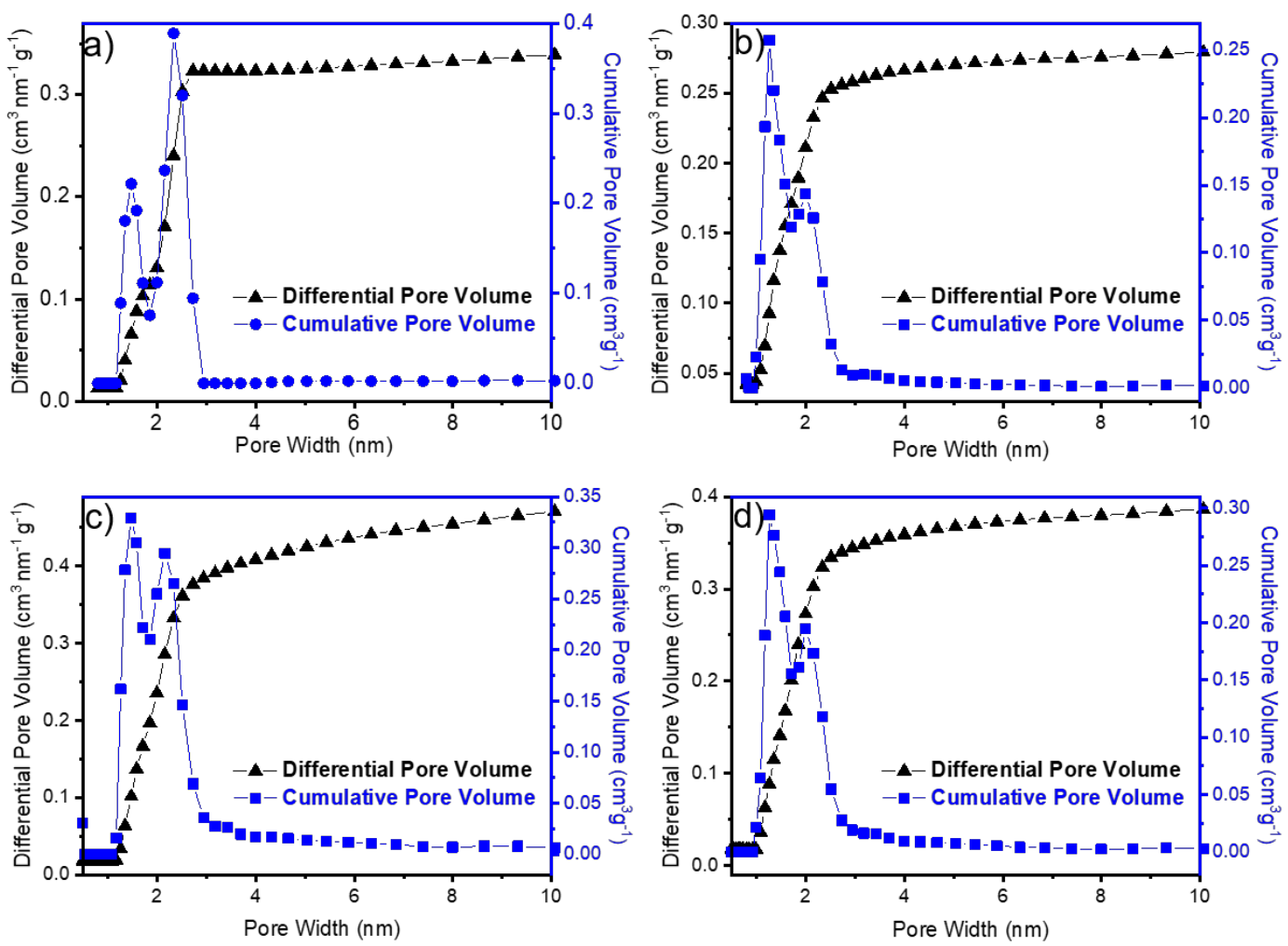

Figure S4. Pore size (blue) and pore size distribution (black) profiles of B-COF-1 (a), B-COF-2 (b), T-COF-1 (c) and T-COF-2 (d).
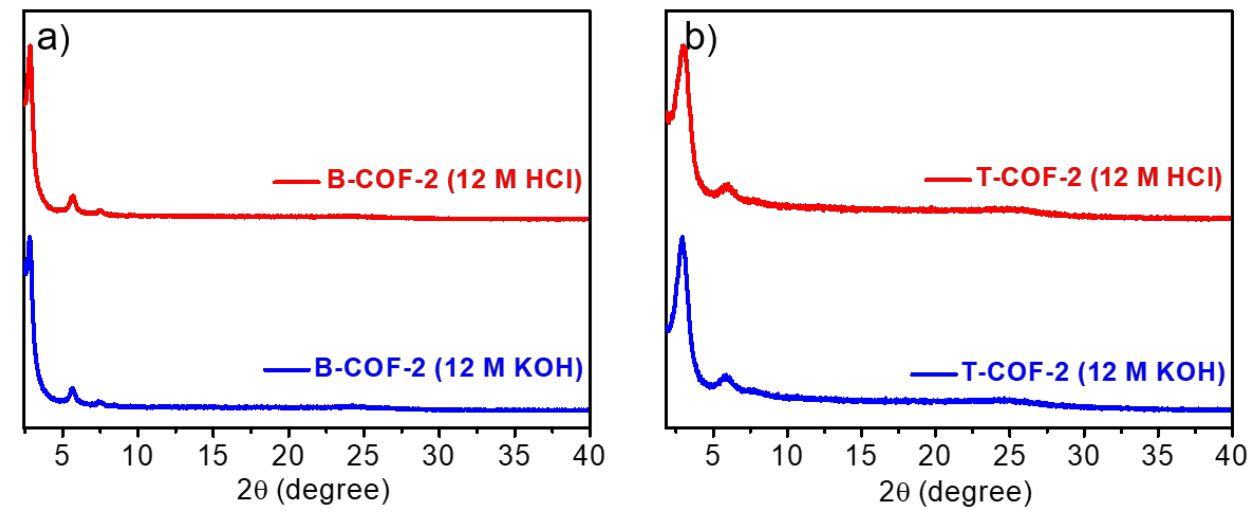

Figure S5. Chemical stability of B-COF-2 and T-COF-2. PXRD patterns of B-COF2 (a) and T-COF-2 (b) after treatment with $12 \mathrm{M} \mathrm{HCl}$ or $12 \mathrm{M} \mathrm{KOH}$ at $50{ }^{\circ} \mathrm{C}$ for 1 day. 


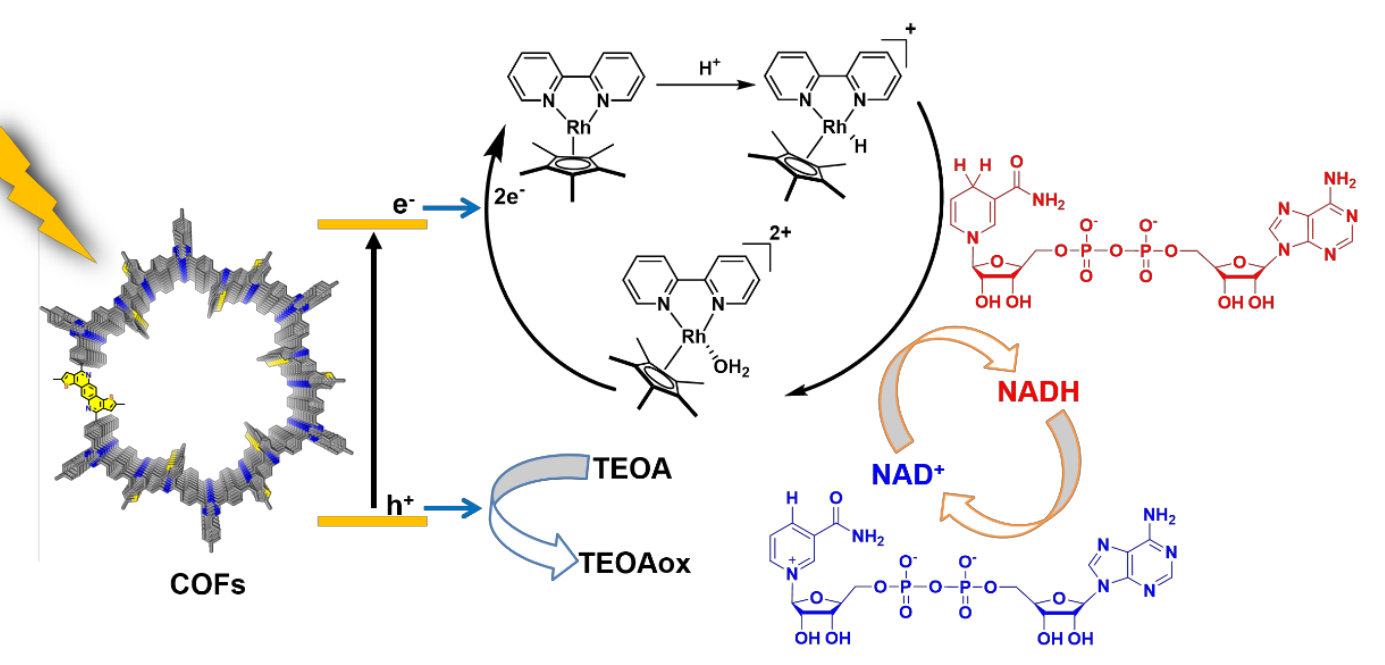

Figure S6. The process of photocatalytic NADH regeneration.

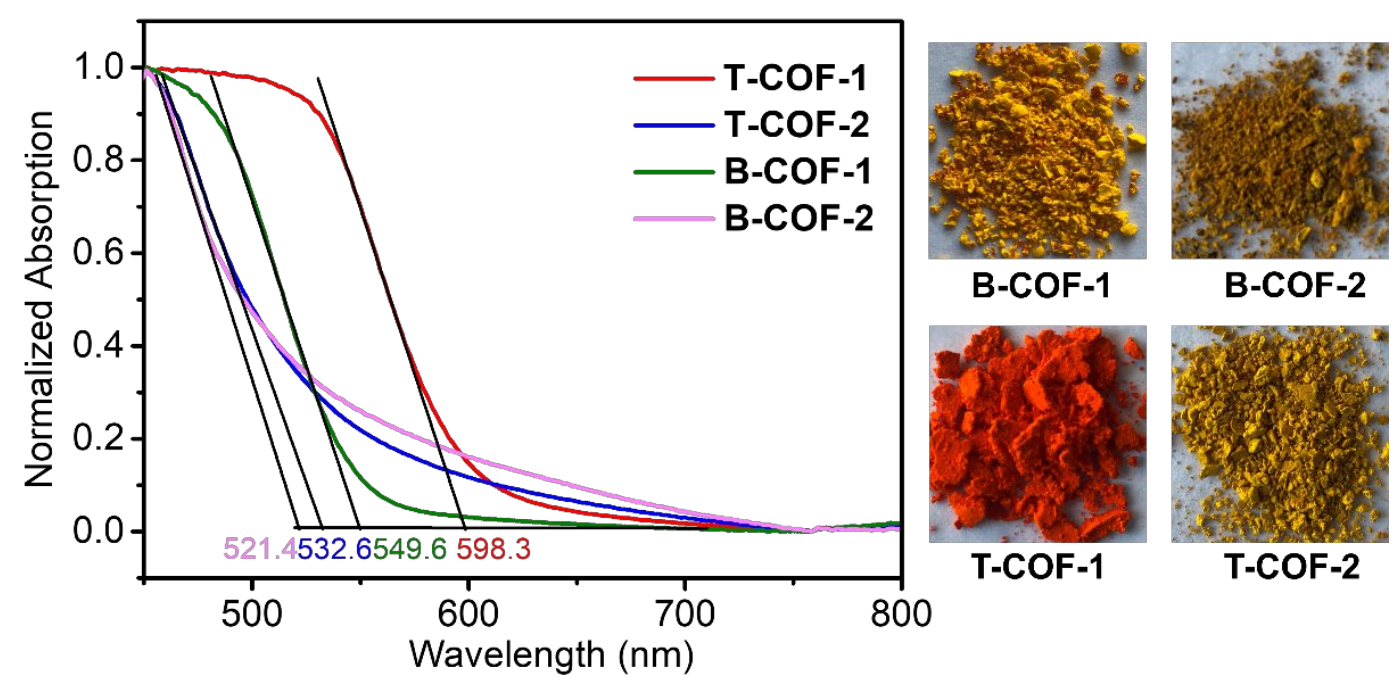

Figure S7. The solid-state absorption spectrum and digital images of B-COF-1, 2 and T-COF-1, 2. 


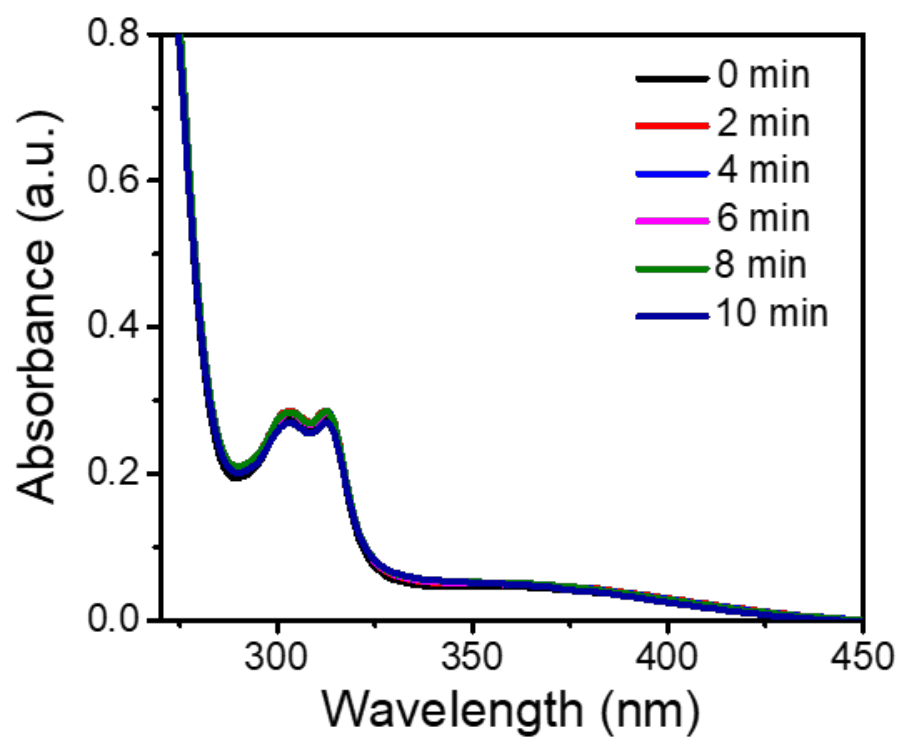

Figure S8. The experimental results of $\mathrm{NADH}$ regeneration without $\mathrm{COFs}$, and the results showed no regeneration occurred.
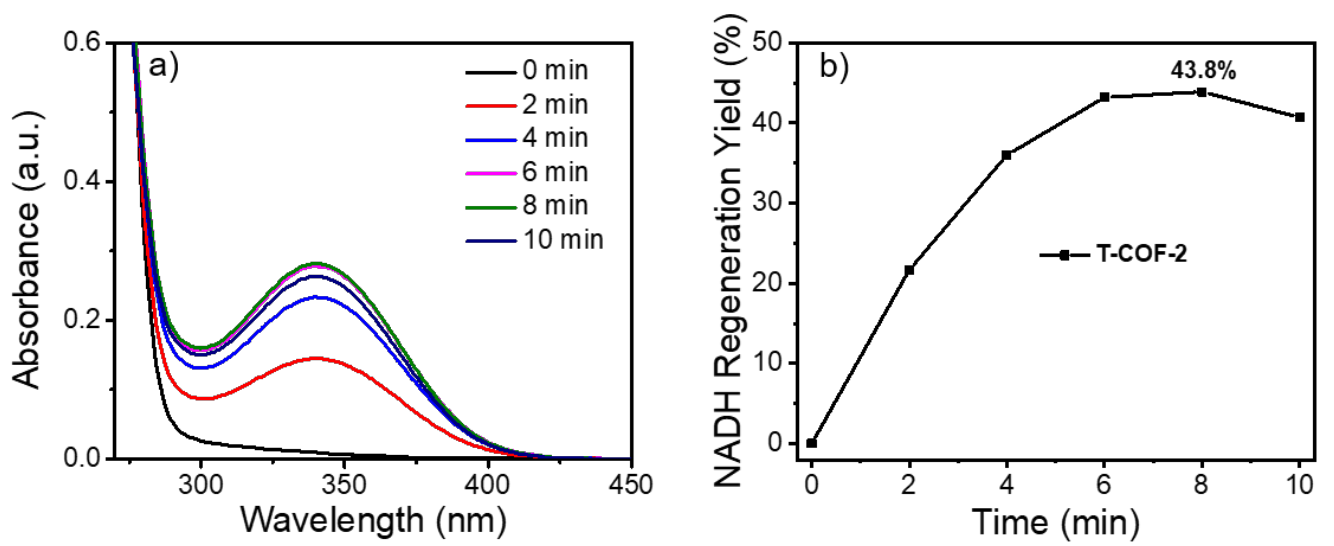

Figure S9. The experimental results of NADH regeneration without the electron mediator M: (a) absorbance changes of NADH (b) photocatalytic NADH regeneration kinetic. 

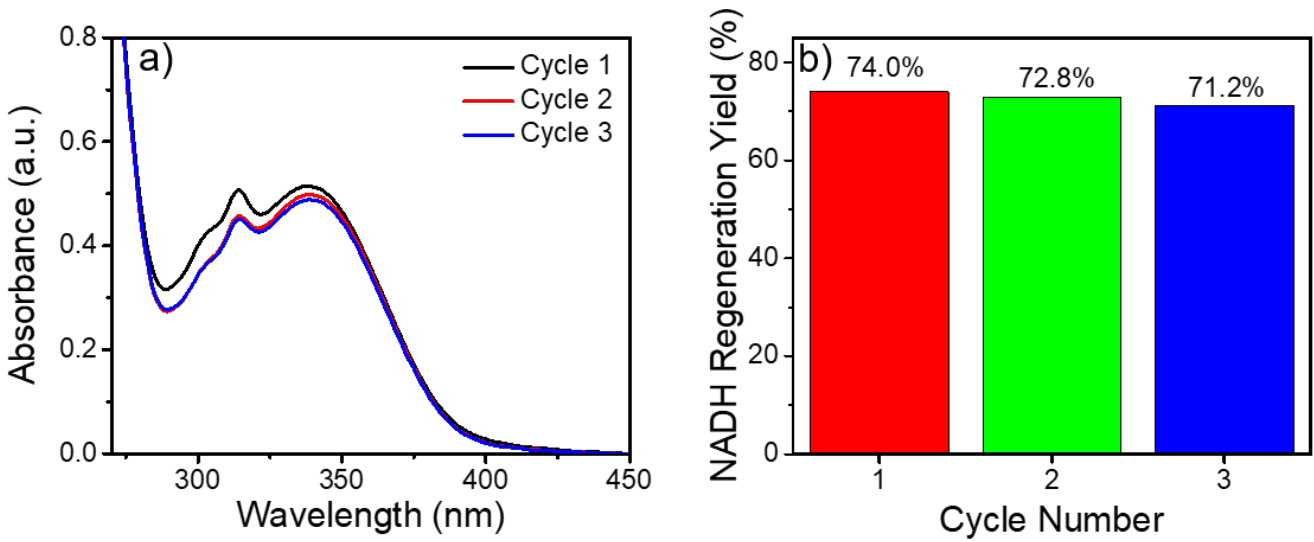

Figure S10. (a-b) Photoregeneration activity of TP-COF during repeated uses. The turnover number was 3 .

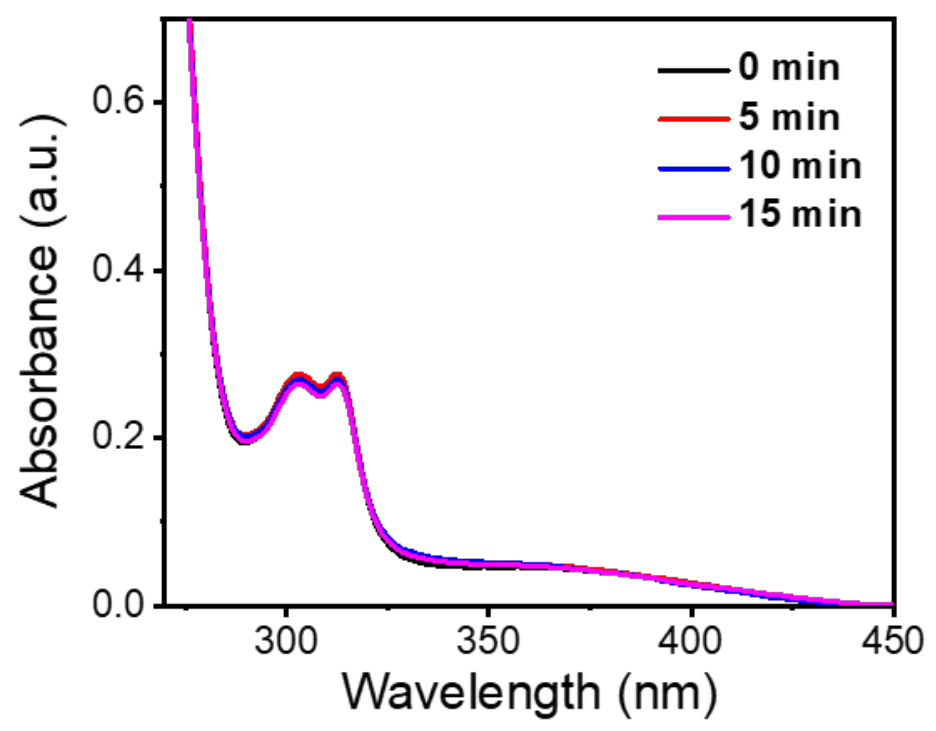

Figure S11. NADH regeneration with model compound Ref-2. 


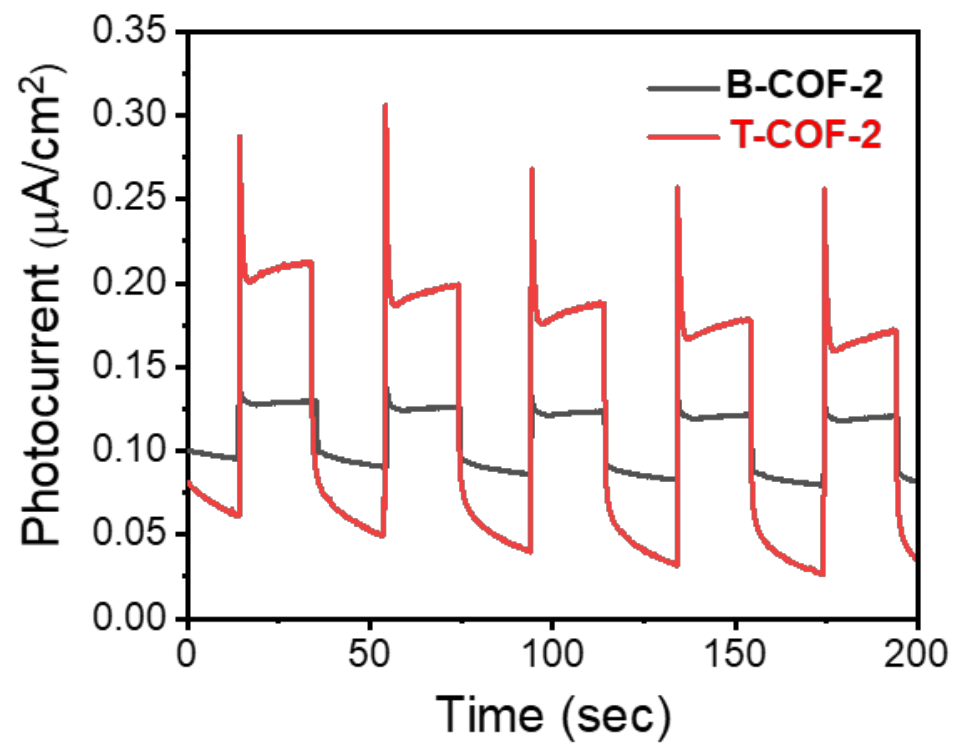

Figure S12. The photocurrent profiles of B-COF-2 and T-COF-2 casted on FTO glass at $0.2 \mathrm{~V}$ bias vs $\mathrm{Ag} / \mathrm{AgCl}$ in a $0.1 \mathrm{M} \mathrm{Na}_{2} \mathrm{SO}_{4}$ solution.
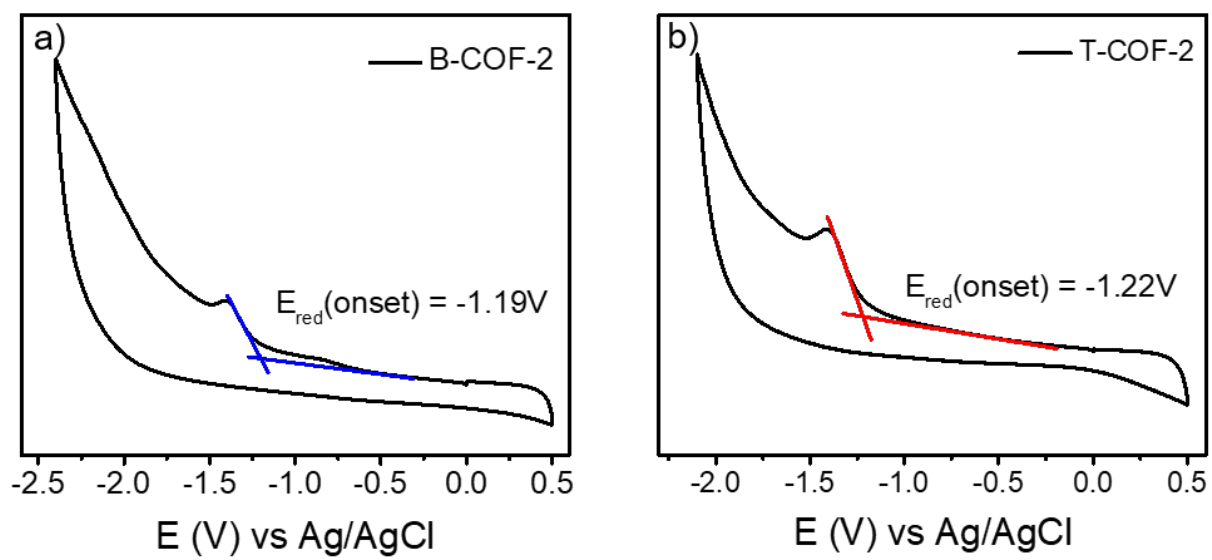

Figure S13. The CV curves of the B-COF-2 (a) and T-COF-2 (b) measured in acetonitrile. 


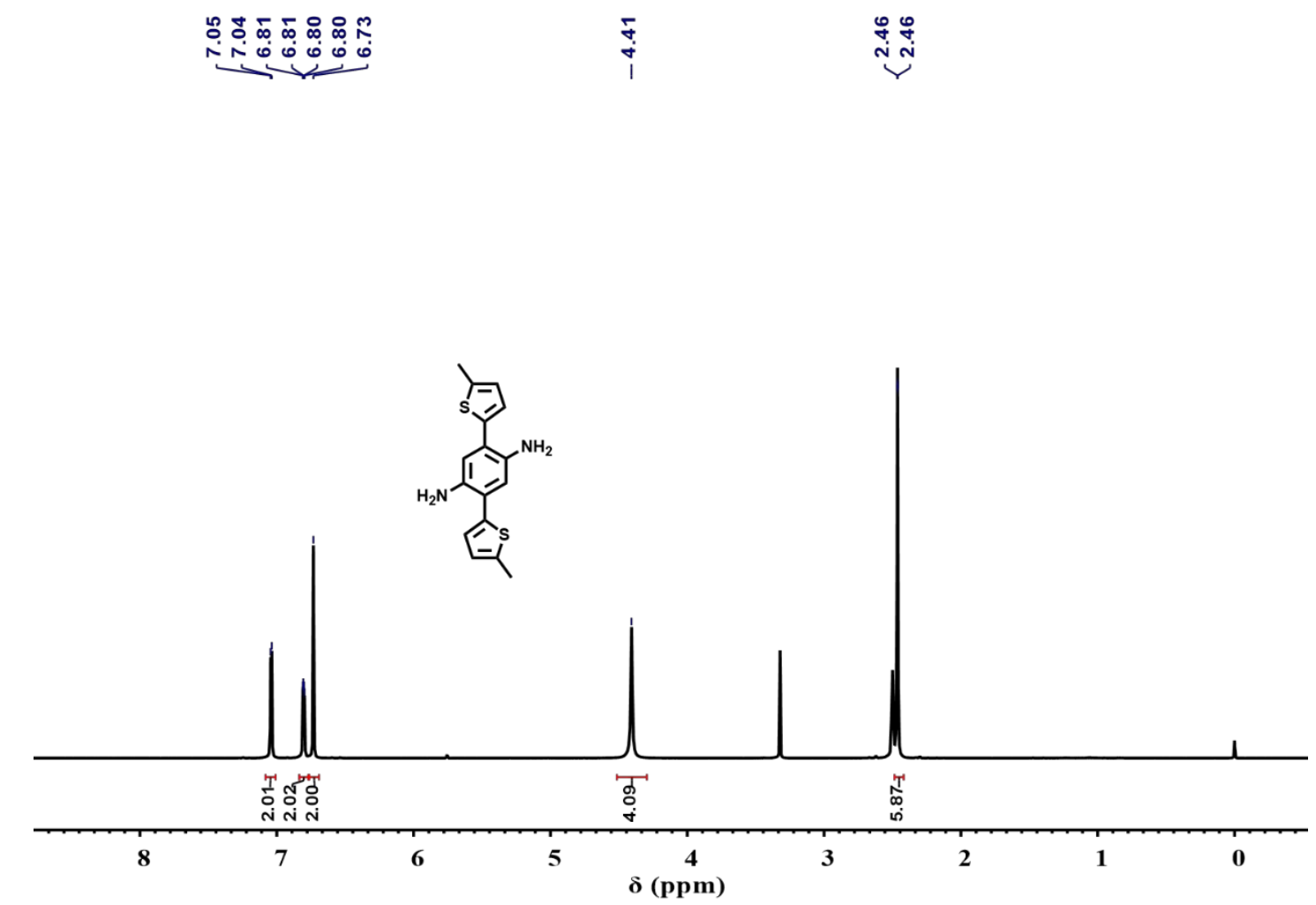

Figure S14. ${ }^{1} \mathrm{H}$ NMR spectrum of compound A.

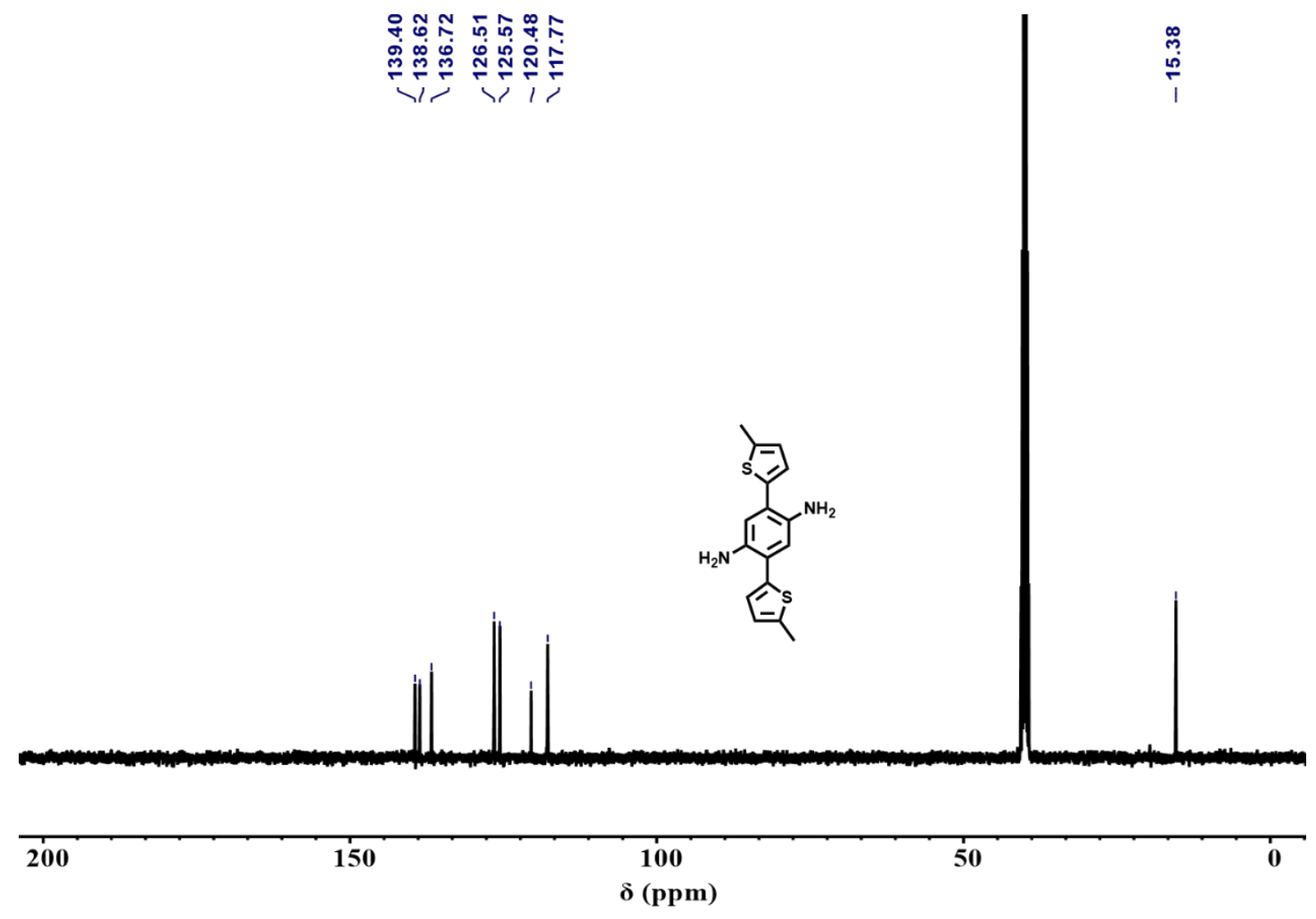

Figure S15. ${ }^{13} \mathrm{C}$ NMR spectrum of compound $\mathbf{A}$. 


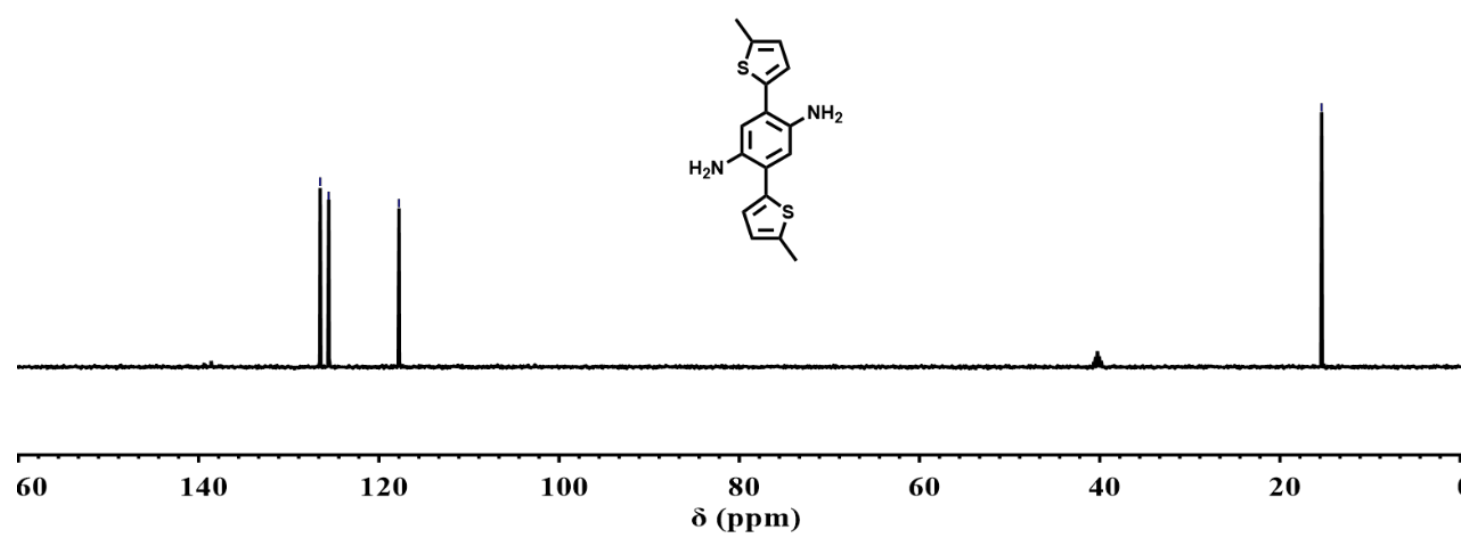

Figure S16. ${ }^{13} \mathrm{C}$ DEPT-135 spectrum of compound A.

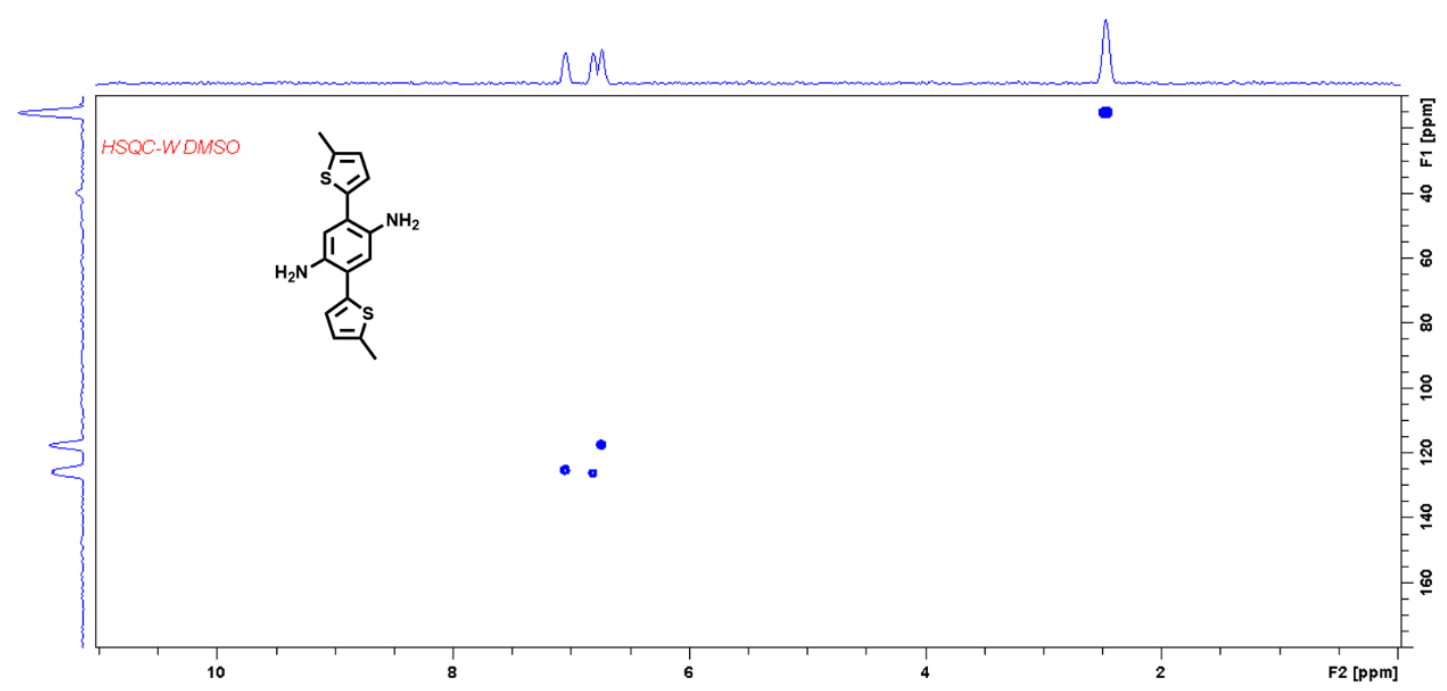

Figure S17. HSQC spectrum of compound A. 


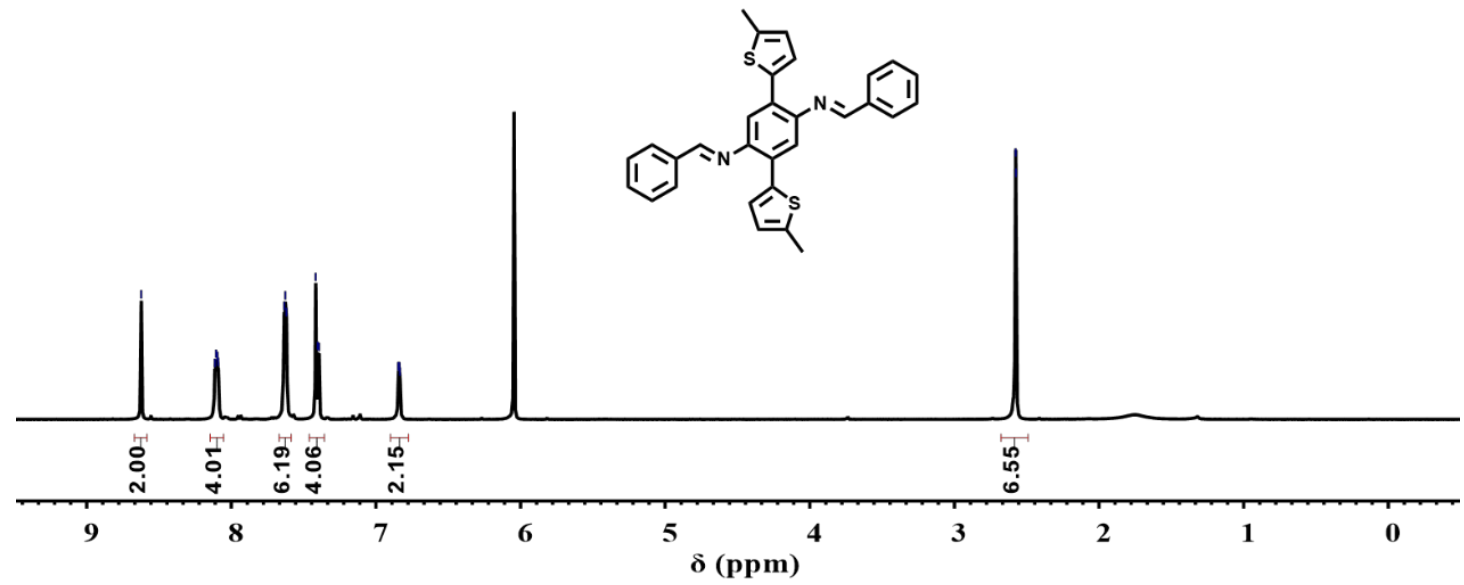

Figure S18. ${ }^{1}$ H NMR spectrum of Ref-1.

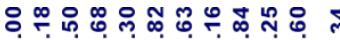

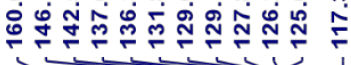

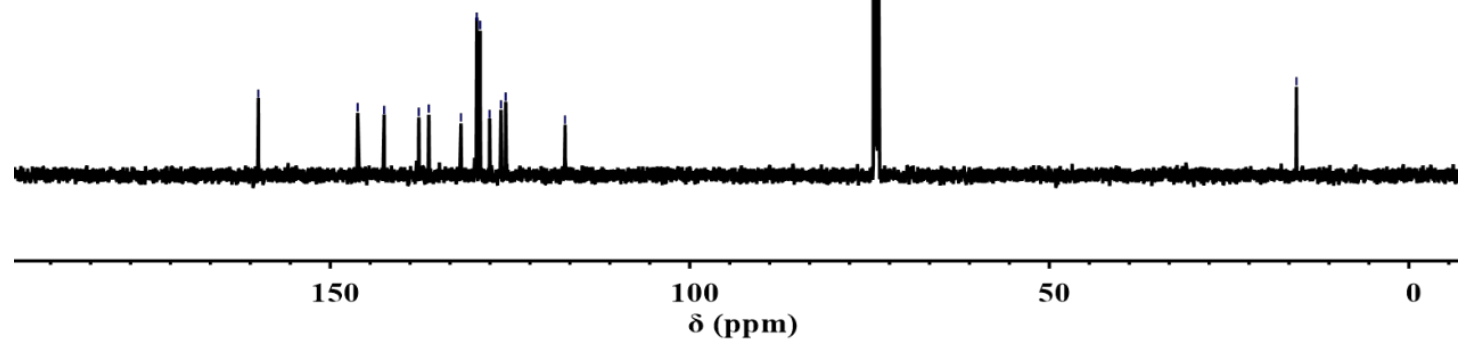

Figure S19. ${ }^{13} \mathrm{C}$ NMR spectrum of Ref-1. 


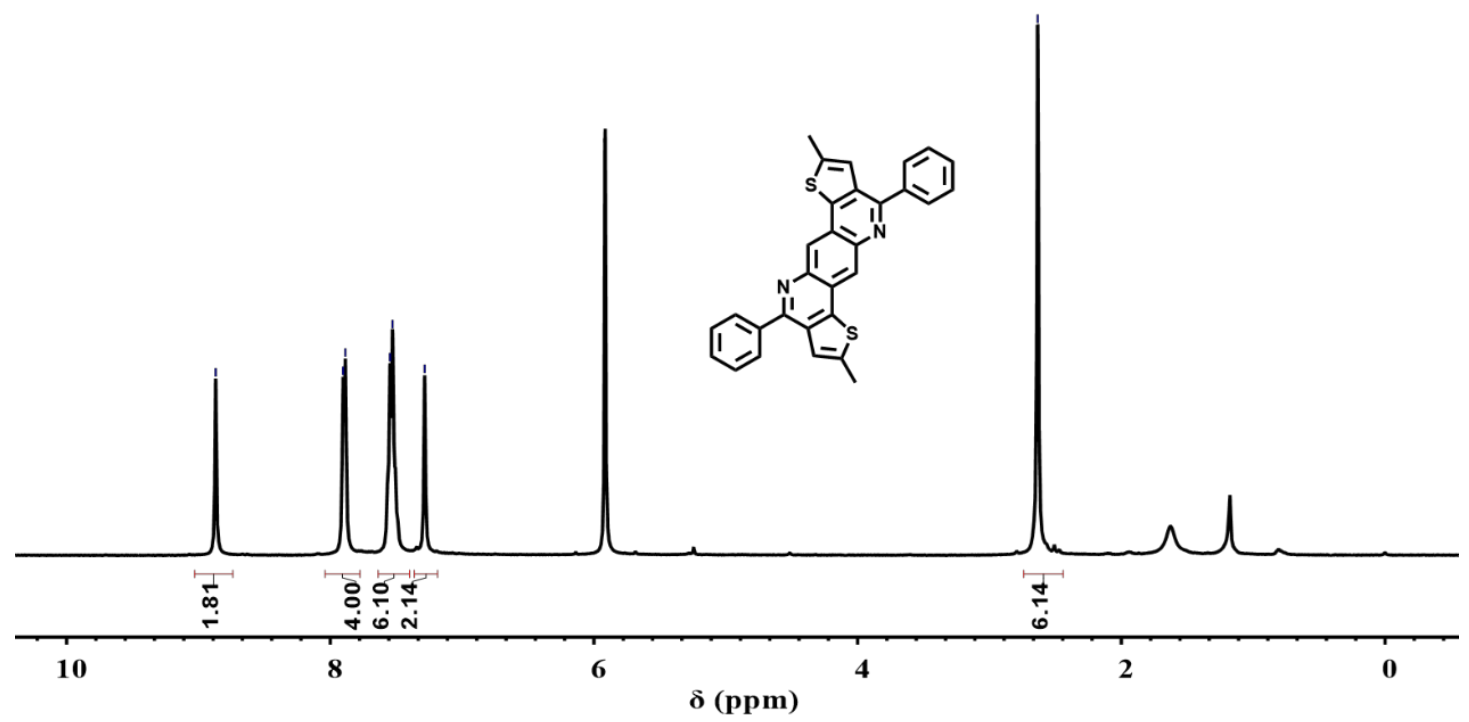

Figure S20. ${ }^{1}$ H NMR spectrum of Ref-2.

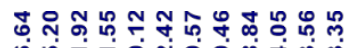

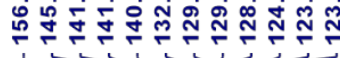

$\stackrel{\substack{+\grave{j}}}{i}$

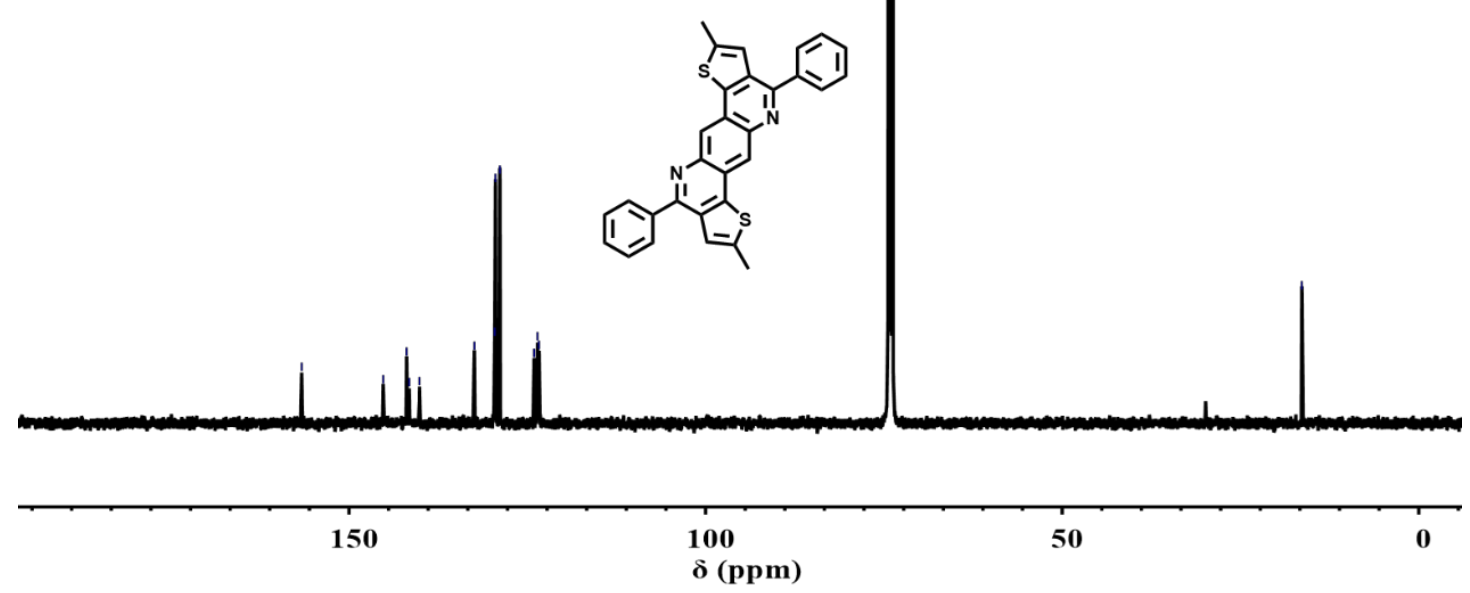

Figure S21. ${ }^{13} \mathrm{C}$ NMR spectrum of Ref-2. 


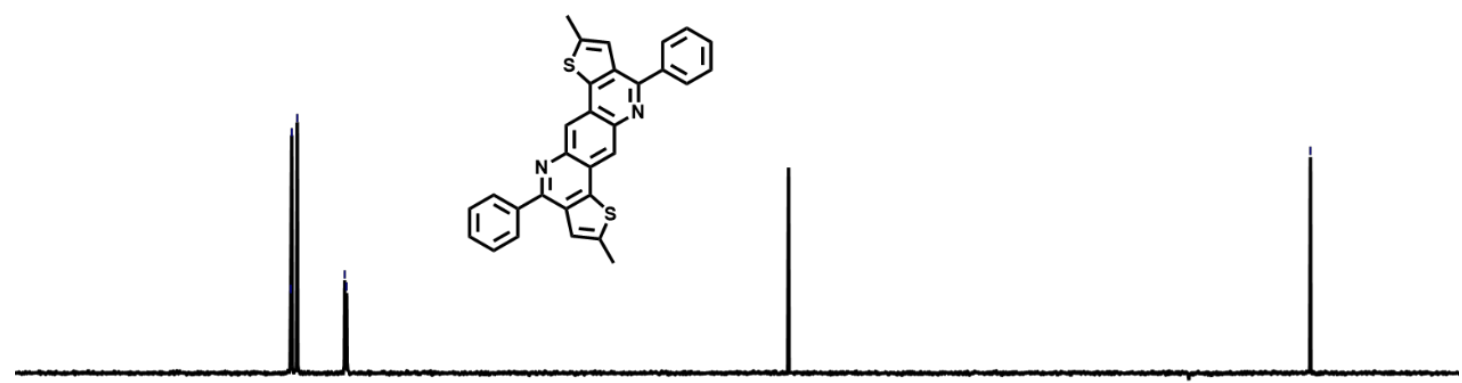

\begin{tabular}{|c|c|c|c|c|c|c|c|}
\hline 60 & 140 & 120 & 100 & $\begin{array}{c}\mathbf{8 0} \\
\delta(\mathbf{p p m})\end{array}$ & 60 & 40 & 20 \\
\hline
\end{tabular}

Figure S22. ${ }^{13} \mathrm{C}$ DEPT-135 spectrum of Ref-2.

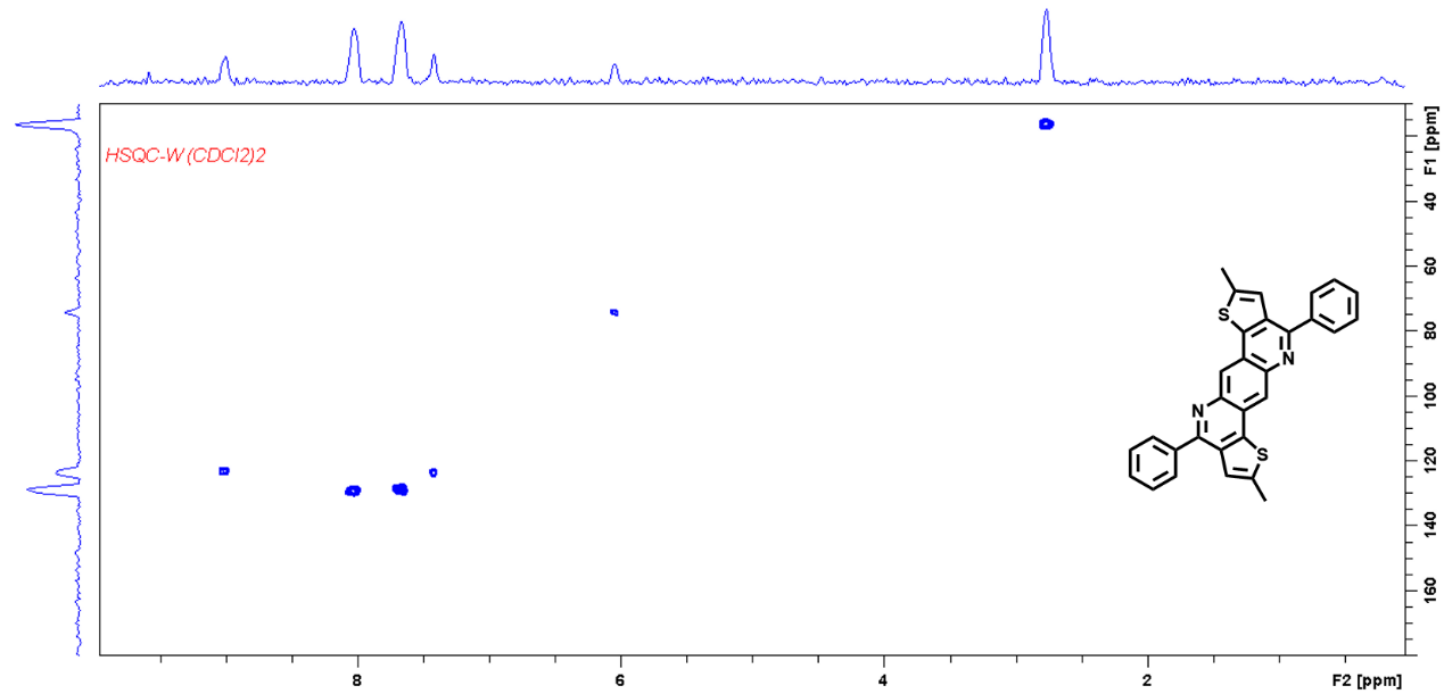

Figure S23. HSQC spectrum of spectrum of Ref-2.

\section{References}

[S1] Greenaway, R. L.; Santolini, V.; Bennison, M. J.; Alston, B. M.; Pugh, C. J.; Little, M. A.; Miklitz, M.; Eden-Rump, E. G. B.; Clowes, R.; Shakil, A.; Cuthbertson, H. J.; Armstrong, H.; Briggs, M. E.; Jelfs, K. E.; Cooper, A. I., Nat. Commun. 2018, 9, 2849.

[S2] Sekizkardes, A. K.; Altarawneh, S.; Kahveci, Z.; İslamoğlu, T.; El-Kaderi, H. M., Macromolecules 2014, 47, 8328-8334. 